\title{
Probiotics and Herbs Combination in Commercial Feed Additives as Growth Promoter in Broiler Chicken
}

\author{
Thomas Emanuel Manggotu Nahak $^{1}$, Agnesia Endang Tri Hastuti Wahyuni',*, \\ Yanuartono $^{3}$, and Charles Rangga Tabbu $^{4}$ \\ ${ }^{1}$ Veterinary Science Study Program, Faculty of Veterinary Medicine, Universitas Gadjah Mada, Jl. \\ Fauna No. 2, Sleman, Yogyakarta \\ ${ }^{2}$ Departement of Microbiology, Faculty of Veterinary Medicine, Universitas Gadjah Mada, Jl. Fauna \\ No. 2, Sleman, Yogyakarta \\ ${ }^{3}$ Departement of Internal Medicine, Faculty of Veterinary Medicine, Universitas Gadjah Mada, Jl. \\ Fauna No. 2, Sleman, Yogyakarta \\ ${ }^{4}$ Depertement of Pathology, Faculty of Veterinary Medicine, Universitas Gadjah Mada, Jl. Fauna No. \\ 2, Sleman, Yogyakarta
}

\begin{abstract}
The prohibition on the use of Antibiotic Growth Promoter (AGP) causes the use of probiotics, herbs, enzymes and organic acids as an alternatives to AGP. This study aimed to determine the role of combination of probiotic and herbs in commercial feed additives on broiler performance. Sixty day-old male broiler were divided into 3 groups where each group consisted of 20 chickens with 4 replication each group. Group I was given commercial feed, group II was given commercial feed + AGP and group III was given commercial feed + combination of probiotics, herbs, enzymes and organic acids. All chickens were kept for 5 weeks. Body weight gain (BWG), body weight (BW) and Feed Convertion Ratio (FCR) were calculated every week. Carcass percentage was calculated at week 5 . The results obtained from BWG and BW on group III at weeks 4 and 5 weeks were higher and significant difference $(\mathrm{P}<0.05)$ compared to groups I and II. The percentage of carcasses between groups did not have a significant difference $(\mathrm{P}>0.05)$. FCR values in group III from week 1 to weeks 5 were lower than groups I and II. The use of combination of probiotics, herbs, enzymes and organic acids has proven to have a good role on broiler performance so that it can replace AGP as a feed additive on broiler.
\end{abstract}

\section{Introdction}

Feed additives are ingredients that are mixed in the livestock feed which can affect health, productivity and nutritional conditions of livestock animals. In the recent decades, antibiotics have been commonly used as the feed additives. Antibiotics are added to animal feed can improve livestock performance, but have negative effects such as residues in tissues, antimicrobial resistance and cross resistance in antimicrobial therapy [1].

*Corresponding author : wahyuni_aeth@ugm.ac.id 
The World Health Organization (WHO) through the Global Strategy for Containment of Antimicrobial Resistance prohibits the use of Antibiotic Growth Promoter (AGP) as an effort to minimize the incidence of antibiotic resistance. The strategy is aimed at governments to take measures to ban the use of antibiotics as a growth promoter in livestock feed. The Indonesian government through the Minister of Agriculture Regulation of the Republic of Indonesia Number 14/PERMENTAN/PK.350/5/2017 has officially prohibited the use of AGP for animal feed additives whose products are consumed by humans. Therefore, nowadays there are a lot of research focused on finding alternatives to antibiotics that are safe and do not have bad side effects [2].These alternative substitutes for AGP such as probiotics, herbs, enzymes and organic acids both independently or in combination.

Probiotics are nonpathogenic living organisms present in some foods which have positive effects on the health of the hosts if they enter the body in sufficient amounts [3]. Probiotics are often combined with several types of feed additives such as enzymes and organic acids. Probiotics, herbs, enzymes and organic acids independently have a good effect on broiler performance such as increase digestive enzyme activity in the gut, nutrient digestibility, villi height, weight gain, carcass percentage and decrease FCR value [4-10].

Probiotics, herbs, enzymes and organic acids independently have a positive effect on performance, therefore a combination of feed additives is needed in order to get the maximum effect. Several previous studies in vivo using a combination of probiotics, prebiotics and organic acids [11] and a combination of probiotics, prebiotics and enzymes [12] revealed that the feed additives combination had a synergistic effect and could improve broiler performance. In vivo studies using combination of probiotic and herbal simultaneously are still rare, but in vitro studies conducted by Prakasita et al. [13] has proven that the combination of probiotics and herbs has a synergistic effect where the administration of media containing extracts from curcuma, red ginger and turmeric can support the growth of probiotics (Lactobacillus acidophilus and Lactobacillus brevis). Therefore, it is necessary to conduct in vivo study using a combination of probiotics, herbs, enzymes and organic acids. This study therefore aimed to determine the role of probiotics, herbs, enzymes and organic acids combination on broiler performance.

\section{Materials and Methods}

\subsection{Ethical Approval}

This study was approved by the Commission of Ethical Clearance Faculty of Veterinary Medicine, Gadjah Mada University (0014/EC-FKH/Int./2019).

\subsection{Experimental Design}

A total of 60 day-old male broilers chickens (Lohmann strain) were divided randomly into 3 groups, where each group consisted of 20 chickens with 4 replication. Each replication was placed in one flock. Group I was a control group that was given basal feed, group II was given a mixture of basal feed and AGP (enramycin) at a dose of $250 \mathrm{gr} / \mathrm{ton}$ (based on the recommended dosage of commercial products) and group III was given a mixture of basal feed and commercial feed additives (combinations of probiotic, herbal, enzyme and organic acid) at a dose of $3 \mathrm{~kg} / \mathrm{ton}$. The combination of probiotic, herbal, enzyme and organic acids is available in the form of Promix ${ }^{\mathrm{TM}}$ commercial feed additives with the composition of the each microbial $6.2 \times 10^{8} \mathrm{CFU} / \mathrm{g}$ (Bacillus subtillis, Bifidobacterium bifidum, Bifidobacterium longum, Lactobacillus acidophilus, Saccharomyces cereviciae), 3\% herbal mix (Zingiber officinale, Curcuma xanthorrhiza, C. domestica, Kaempferia galanga), enzymes 
(proteolytic, amylolytic, lipolytic, cellulolytic) and organic acids (lactic acid and acetic acid). Promix $^{\mathrm{TM}}$ compositions are based on a composition table listed on the product packaging.

\subsection{Managing and Vaccination}

The chickens were maintained and treated for 5 weeks. All chickens were vaccinated on day 1 with live ND + IB vaccine (spray), live IBD (subcutaneous) and ND killed (subcutaneous) and booster vaccine was given on day 18 with live ND vaccine (intraocular). Maintenance was carried out at the Center of Innovation and Agrotechnology UGM. Group division was done by dividing the chickens into 12 pens. Each pen consists of 5 individuals. Feeding was carried out in ad libitum. The commercial feed used was an AGP-free basal feed. The composition of basal feed can be seen in Table 1 (basal feed composition is obtained from the commercial feed composition table and according to nutritional requirements for broiler chickens). The drinking water was provided using chlorinated water at a dose of 2-5 ppm.

Table 1. Nutritional content of basal feed

\begin{tabular}{|l|c|c|c|}
\hline \multirow{2}{*}{ Nutritional Content } & \multicolumn{3}{|c|}{ Feeding Phase } \\
\cline { 2 - 4 } & Pre-starter & Starter & Finisher \\
\hline Water content (\%) Max & 13 & 13 & 13 \\
\hline Protein (\%) & $23,0-25,0$ & $22,0-24,0$ & $20,0-23,0$ \\
\hline Fat (\%) Min & 4 & 4 & 5 \\
\hline Ash (\%) Max & 7 & 7 & 8 \\
\hline Crude fibre (\%) Max & 5 & 5 & 5 \\
\hline Ca (\%) Min & 0,9 & 0,9 & 0,9 \\
\hline P (\%) Min & 0,6 & 0,6 & 0,6 \\
\hline Lysin (\%) Min & 1,32 & 1,19 & 1,05 \\
\hline Methionine (\%) Min & 0,50 & 0,48 & 0,43 \\
\hline Methionine + cysteine (\%) Min & 0,98 & 0,89 & 0,82 \\
\hline Tryptophan (\%) Min & 0,20 & 0,19 & 0,19 \\
\hline Threonine (\%) Min & 0,86 & 0,78 & 0,71 \\
\hline
\end{tabular}

\subsection{Performance Parameters}

Body weight (BW) were calculated every week from week 1 to week 5. From BW data obtained, then body weight gain (BWG) were calculated with formula $B W_{n}=B W_{n}-B W_{n}$ 1. All chicken were weighed individually and then averaged as a group value. Chicken weighing was done in the morning before being given food and drinking water. Feed Conversion Ratio (FCR) was calculated every week from week 1 to week 5 by dividing total feed consumption by total body weight every week. The total feed consumption and total body weight were measured at the same time by each group. Five chickens were taken randomly from each group at week 5 and then slaughtered to calculate the carcass percentage. The carcass percentage is the percentage of the carcass weight of the life weight of the chicken. 


\subsection{Statistical Analysis}

Data on weight gain, body weight and carcass percentage were analysed using the One-Way ANOVA test on statistical program (SPSS 24). If significant differences were found, the test would be continued with the Duncan's test to find out the difference in mean value between groups. The data would be presented in the form of mean \pm standard deviation (Mean $\pm \mathrm{SD}$ ). The significant level used is $\mathrm{P}<0.05$.

\section{Result and Discussion}

\subsection{Body Weight Gain and Body Weight}

Based on the data obtained (Table 2), there was no significant difference ( $\mathrm{P} \geq 0.05)$ of $\mathrm{BWG}$ from the week 1 to the week 3 between groups. In the week 4, group III had a higher BWG and significant difference $(\mathrm{P} \leq 0.05)$ compared to groups I and II. In the week 5, group III had a higher $\mathrm{BWG}$ and significant difference $(\mathrm{P} \leq 0.05)$ compare to group I. There was no significant difference $(\mathrm{P} \geq 0.05)$ of $\mathrm{BW}$ between groups starting from week 1 to week 3 . Significant differences are observed in the week 4 and week 5 . In the week 4 , group III had higher BW and significant difference $(\mathrm{P} \leq 0.05)$ compared to groups I and II. The same results also occurred at week 5 where group III had a higher BW and significant difference $(\mathrm{P} \leq 0.05)$ compared to groups I and II (Table 2).

Previous studies have proven that the use of probiotics (B. subtilis) [14], herbs $(Z$. officinale and Allium sativum) [15], enzymes (xylanase, $\beta$-glucanase, invertase, protease, cellulase, amylase, mannanase) [16] as well as organic acid (fumaric acid, citric acid and malic acid) [17] can increase BWG and BW in broilers. Broilers in group III was given a combination of herbal probiotic enzymes and organic acids, its BWG and BW were higher than other group because the feed additives can increase nutrient digestibility and absorption [18], increase digestive enzyme activity [19] and modulating immune system in the digestive tract [20].

Significant differences in BW and BWG between groups can be seen in the week 4 and week 5, where group III has a higher BW and BWG than groups I and II. This shows that feed additives already have a positive effect. The positive effect is due to the mechanism of action of feed additives such as probiotics, herbs, enzymes and organic acids can increase nutrient digestibility, absorption, and increase digestive enzyme activity. In addition, it is also caused by the growth of intestinal villi in broiler chickens that have been maximized at the age of 4 weeks so that the absorption of nutrients from the feed consumed can be maximized [21]. 
Table 2. Body weight (BW) and body weight gain (BWG) between groups from week 1 to 5

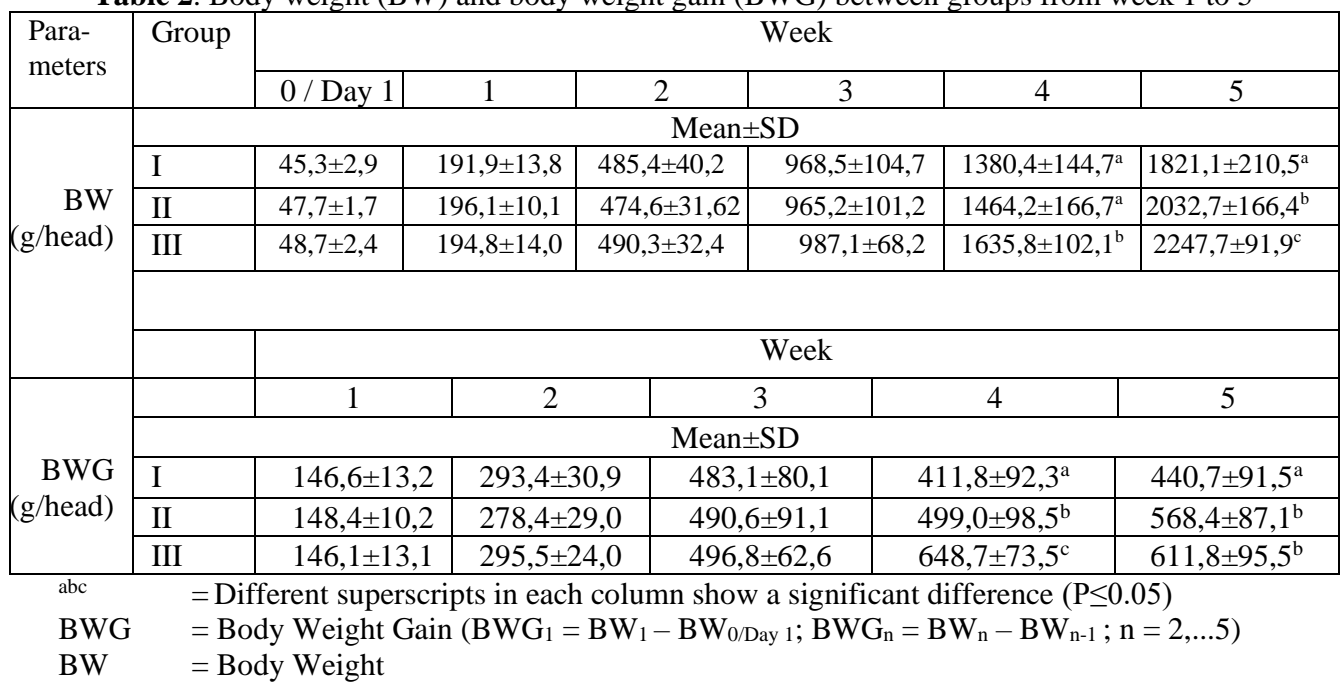

\subsection{Carcass Percentage}

There was no significant difference $(\mathrm{P} \geq 0.05)$ of the carcass percentage at week 5 between groups (Table 3 ). The carcass percentage between groups is in the range of $69.51 \%-69.56 \%$. Although the results of BW and BWG data show a significant difference, but in the carcass percentage data there is no significant difference. The results of this study are similar to studies which were conducted by several researchers who used herbs (cinnamon oil) and organic acids (sodium butyrate) combination [22], herbs (Z. officinale) and probiotics $(L$. acidophilus, L. casei , E. faecium and B. thermophilum) combination [23] and organic acids (formic acid and propionic acid) herbs (Origanum onites, Syzygium aromaticum, Cuminum cyminum) [24] in broiler feed did not effect on carcass percentage. The results of this study are supported by research conducted by [25] who revealed that the use of probiotics (Bacillus subtilis) in broiler feed had a significant effect on body weight but did not significantly influence the carcass percentage. Furthermore, although no significant effect on carcass percentage overall but significantly affect the percentage of the chest muscle. This shows that although there is no effect on the overall carcass weight, but there is the possibility of giving feed additives can affect the carcass pieces.

Table 3. Carcass percentage between groups at week 5

\begin{tabular}{|l|c|c|c|}
\hline \multirow{2}{*}{ Parameter } & \multicolumn{3}{|c|}{ Group } \\
\cline { 2 - 4 } & I & II & III \\
\hline $\begin{array}{l}\text { Carcass Percentage } \\
(\% / \text { head })\end{array}$ & $69,51 \pm 3,8$ & $69,51 \pm 0,9$ & $69,56 \pm 2,4$ \\
\hline Significance Level & \multicolumn{3}{|c|}{ NS } \\
\hline
\end{tabular}

\subsection{Feed Convertion Ratio}

Group III from week 1 to week 5 have a lower FCR value compared to groups I. Group III have a lower FCR value at week 1, week 2, week 4 and week 5 compared to groups II. At week 1 up to week 3, BW and BWG is not significant different beetwen groups, but FCR is 
significant different, it shows that group III has better feeding efficiency compared to groups I and II. A low FCR value showed that the food consumed is efficiently utilized to increase body weight (Figure 1).

Similar results were also obtained from several previous studies that used probiotics, herbs, enzymes and organic acids supplements both independently and in combination. Research using enzymes (phytase, xylanase, amylase and protease) and probiotics ( $B$. amyloliquefaciens) in broiler feed revealed that the use of enzyme both independently or in combination with probiotics can decrease FCR value compared to control group [12]. The study using probiotics and citric acid combination revealed that the use of combination a probiotics and organic acids significantly decrease FCR values compared to control group [26]. A good FCR values in the group given a combination of probiotics, herbs, enzymes and organic acids are due to the feed additives used can increase cellulase enzyme activity, crude fibre and dry matter digestibility $[17,18,24]$.

The results of this study in the form of good performance indicate that the feed combination used has a synergistic effect. This synergistic effect focuses on probiotics and herbs which are the ingredients of the feed additives used. Several previous studies have also proven that herbs added to yogurt can maintain viability of probiotic bacteria (L. Bulgaricus and L. acidophilus) for 29 days of storage [27]. The results of this studies show that in fact, probiotics and herbs have a synergistic effect in which herbs can act as probiotics which can be a source of nutrition for probiotic bacteria. The carbohydrate content of herbal extracts can act as a substrate for bacterial growth. Besides that, the content of polyphenols in herbal extracts has high antioxidant activity against free radicals and oxidative stress arising from metabolic activity and can support the growth of probiotic bacteria by providing a microaerophilic environment [28].

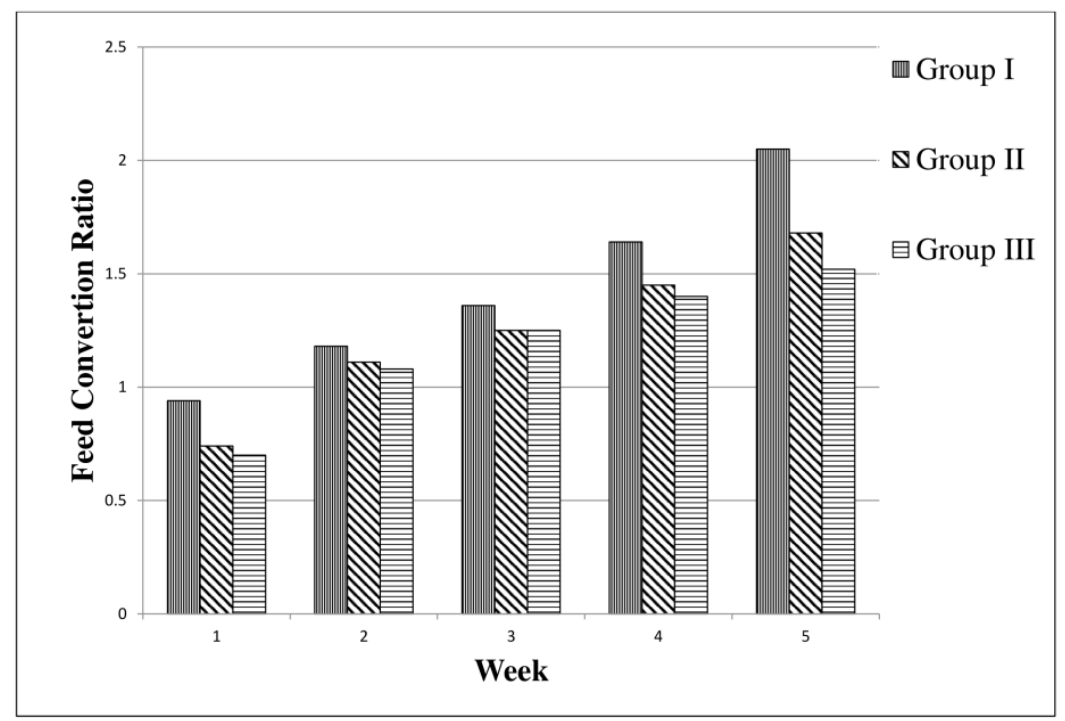

Figure 1. Feed Conversion Ratio each groups from week 1 to week 5. 


\section{Conclusion}

The combination of probiotic and herbs in commercial feed additives Promix ${ }^{\mathrm{TM}}$ has a synergistic effect and good role on growth performance of broiler such as increasing BWG, BW and decreasing FCR value so that it can replace AGP as a feed additives in broilers.

The writers would like to express gratitude to the head office of the Center of Innovation and Agrotechnology UGM who has granted us the permission to use chicken coops to conduct research for 5 weeks. Thanks also goes to drh. Agnes Heratni, MP who has prepared feed additives.

\section{References}

1. Y. Mehdi, M.P. Létourneau-Montminy, M.L. Gaucher, Chorfi Y, Suresh G, Rouissi T, Brar SK, Côté C, Ramirez AA, Godbout S. Use of antibiotics in broiler production: Global impacts and alternatives. Anim. Nutr. 4, 170-178 (2018).

2. M.H. Kogut, R.J. Arsenault. Editorial: Gut Health: The New Paradigm in Food Animal Production. Front. Vet. Sci. 2016 Aug 31, 71 (2016).

3. S.K. Kim, R.B. Guevarra, Y.T. Kim, Kwon J, Kim H, Cho J.H, Kim H.B, Lee J.H. Role of Probiotics in Human Gut Microbiome-Associated Diseases. J. Microbiol Biotechnol. 29, 1335-1340 (2019).

4. S. Adil, T. Banday, G.A. Bhat, Mir M.S, Rehman M. Effect of dietary supplementation of organic acids on performance, intestinal histomorphology, and serum biochemistry of broiler chicken. Vet Med Int. (2010).

5. H. Zangiabadi, M. Torki. The effect of a beta-mannanase-based enzyme on growth performance and humoral immune response of broiler chickens fed diets containing graded levels of whole dates. Trop Anim Health Prod. 42, 1209-17 (2010).

6. S.P. Bai, A.M. Wu, X.M. Ding, Lei Y, Bai J, Zhang K.Y, Chio J.S. Effects of probioticsupplemented diets on growth performance and intestinal immune characteristics of broiler chickens. Poult Sci. 92, 663-70 (2013).

7. R. Habibi, G. Sadeghi, A. Karimi. Effect of different concentrations of ginger root powder and its essential oil on growth performance, serum metabolites and antioxidant status in broiler chicks under heat stress. Br Poult Sci. 55, 228-37 (2014).

8. H.M. Abdel-Hafeez, E.S.E. Saleh, S.S. Tawfeek, Youssef I.M.I, Abdel-Daim ASA. Effects of probiotic, prebiotic, and synbiotic with and without feed restriction on performance, hematological indices and carcass characteristics of broiler chickens. Asian-Australas J Anim Sci. 30, 672-682 (2017).

9. S. Yadav, P.Y. Teng, Souza Dos Santos T, Gould R.L, Craig S.W, Lorraine Fuller A, Pazdro R, Kim W.K. The effects of different doses of curcumin compound on growth performance, antioxidant status, and gut health of broiler chickens challenged with Eimeria species. Poult Sci. 99, 5936-5945 (2020).

10. X. Yang, H. Xin, C. Yang, X. Yang. Impact of essential oils and organic acids on the growth performance, digestive functions and immunity of broiler chickens. Anim Nutr. 4, 388-393 (2018).

11. A.S. Salah, O.A. Ahmed-Farid, M.S. El-Tarabany. Carcass yields, muscle amino acid and fatty acid profiles, and antioxidant indices of broilers supplemented with synbiotic and/or organic acids. J Anim Physiol Anim Nutr (Berl). 103, 41-52 (2019).

12. A.L. Wealleans, M.C. Walsh, L.F. Romero, V. Ravindran. Comparative effects of two multi-enzyme combinations and a Bacillus probiotic on growth performance, 
digestibility of energy and nutrients, disappearance of non-starch polysaccharides, and gut microflora in broiler chickens. Poult Sci. 96, 4287-4297 (2017).

13. V.C. Prakasita, W. Asmara, S. Widyarini, A.E.T.H. Wahyuni. Combinations of herbs and probiotics as an alternative growth promoter: An in vitro study. Vet World. 12, 614620 (2019).

14. I. Park,Y. Lee,D. Goo, N.P. Zimmerman, A.H. Smith, T. Rehberger, H.S. Lillehoj. The effects of dietary Bacillus subtilis supplementation, as an alternative to antibiotics, on growth performance, intestinal immunity, and epithelial barrier integrity in broiler chickens infected with Eimeria maxima. Poult Sci. 99, 725-733 (2020).

15. V.K. Karangiya, H.H. Savsani, S.S. Patil, D.D. Garg, K.S. Murthy, N.K. Ribadiya, Vekariya S.J. Effect of dietary supplementation of garlic, ginger and their combination on feed intake, growth performance and economics in commercial broilers. Vet World. 9, 245-50 (2016).

16. J. Sanchez, A. Thanabalan, T. Khanal, R. Patterson, B.A. Slominski, E. Kiarie. Growth performance, gastrointestinal weight, microbial metabolites and apparent retention of components in broiler chickens fed up to $11 \%$ rice bran in a corn-soybean meal diet without or with a multi-enzyme supplement. Anim Nutr. 5, $41-48$ (2019).

17. D.H. Nguyen, I.H. Kim. Protected Organic Acids Improved Growth Performance, Nutrient Digestibility, and Decreased Gas Emission in Broilers. Animals (Basel). 10, 416 (2020).

18. P. Rodjan, K. Soisuwan, K. Thongprajukaew, Y. Theapparat, S. Khongthong, Jeenkeawpieam J, Salaeharae T. Effect of organic acids or probiotics alone or in combination on growth performance, nutrient digestibility, enzyme activities, intestinal morphology and gut microflora in broiler chickens. J Anim Physiol Anim Nutr (Berl). 102, e931-e940 (2018).

19. M.S. Sumon, F. Ahmmed, S.S. Khushi, M.K. Ahmmed, M.A. Rouf, M.A.H. Chisty, Sarower M.G. Growth performance, digestive enzyme activity and immune response of Macrobrachium rosenbergii fed with probiotic Clostridium butyricum incorporated diets. Journal of King Saud University - Science. 30, 21-28 (2018).

20. U. Gadde,S.T. Oh, Y.S. Lee, E. Davis, N. Zimmerman, Rehberger T, Lillehoj H.S. The Effects of Direct-fed Microbial Supplementation, as an Alternative to Antibiotics, on Growth Performance, Intestinal Immune Status, and Epithelial Barrier Gene Expression in Broiler Chickens. Probiotics Antimicrob Proteins. 9, 397-405 (2017).

21. M. Nasrin, M. Siddiqi, M.A. Masum, Wares M.A. Gross and histological studies of digestive tract of broilers during postnatal growth and development. Journal of the Bangladesh Agricultural University. 10, 69-77 (2012).

22. G. Gomathi, S. Senthilkumar, A. Natarajan, R. Amutha, M.R. Purushothaman. Effect of dietary supplementation of cinnamon oil and sodium butyrate on carcass characteristics and meat quality of broiler chicken. Vet World. 11, 959-964 (2018).

23. M. Qorbanpour, T. Fahim, F. Javandel, M. Nosrati, Paz E, Seidavi A, Ragni M, Laudadio V, Tufarelli V. Effect of Dietary Ginger (Zingiber officinale Roscoe) and Multi-Strain Probiotic on Growth and Carcass Traits, Blood Biochemistry, Immune Responses and Intestinal Microflora in Broiler Chickens. Animals (Basel). 8, 117 (2018).

24. H. Basmacioğlu-Malayoğlu, P. Ozdemir, H.A. Bağriyanik. Influence of an organic acid blend and essential oil blend, individually or in combination, on growth performance, carcass parameters, apparent digestibility, intestinal microflora and intestinal morphology of broilers. Br Poult Sci. 57, 227-34 (2016). 
25. M. Yadav, M. Dubey, M. Yadav, K.S. Shankar. Effect of Supplementation of Probiotic (Bacillus subtilis) on Growth Performance and Carcass Traits of Broiler Chickens. Int J Curr Microbiol App Sci. 7, 4840-4849 (2018).

26. M.S. Jasim, A.A. Fehan. Application of Probiotic with Different levels of Citric Acid Supplementation in the Diet for Promotes the Production Efficiency of Broiler Chickens. J Agri Vet Sci. 10, 50-57 (2017).

27. M. Michael, R.K. Phebus, K.A. Schmidt. Plant extract enhances the viability of Lactobacillus delbrueckii subsp. bulgaricus and Lactobacillus acidophilus in probiotic nonfat yogurt. Food Sci Nutr. 3, 48-55 (2015).

28. Q. Zhou, S. Wang, G. Yang, W. Zhao, H.L. Li. Development and evaluation of herbal formulation with antipathogenic activities and probiotics stimulatory effect. J Integr Agric. 15, 1103-1111(2016). 